\title{
Adult acute respiratory distress syndrome due to human parvovirus B19 infection after cardiac surgery: a case report
}

\author{
Min Ma ${ }^{1}$, Xiaojun $\mathrm{Ma}^{2}$, Ming Jia ${ }^{1}$, Xiaotong $\mathrm{Hou}^{1}$ and Hong Wang ${ }^{1 *}$ (i)
}

\begin{abstract}
Background: Infection with human parvovirus B19 (PB19) is very common in pediatric patients. Symptoms and signs depend on the infected patient's immune and hematopoietic status and can range from an asymptomatic condition to life-threatening disease.

Case presentation: A 69-year-old man received elective mitral valvular replacement and tricuspid valvuloplasty under cardiopulmonary bypass and suffered acute respiratory distress syndrome on postoperative day 8 . Through the detection of positive serum IgM and human PB19-specific nucleic acids in serum and bronchoalveolar lavage fluid via metagenomic next-generation sequencing (mNGS), acute human PB19 infection was confirmed. The patient was ventilated and the pulmonary infiltration was attenuated six days later.

Conclusion: A combination of serum human PB19 DNA by mNGS and positive serum human PB19 IgM could provide higher diagnostic sensitivity for acute human PB19 infection. The method of mNGS may be a new choice for detecting rare or atypical pathogens in severe complicated pneumonia. The infection of human PB19 was possibly self-limited.
\end{abstract}

Keywords: Human parvovirus B19, Infection, Acute respiratory distress syndrome, Cardiac surgery

\section{Background}

Human PB19 is a small nonenveloped single-stranded DNA virus that is the only known parvovirus that affects humans [1]. It was first discovered in 1975, and recent clinical research has found that the infection is associated with human diseases [2]. Human PB19 has been recognized to be related to childhood erythema infectiosum (fifth disease), arthropathy, and severe anemia [1, 3]. However, acute respiratory distress syndrome (ARDS) caused by human PB19 infection after cardiac surgery is rarely reported. Here, we report a patient with ARDS

\footnotetext{
*Correspondence: wanghong@mail.ccmu.edu.cn

${ }^{1}$ Center for Cardiac Intensive Care, Beijing Anzhen Hospital, Capital Medical University, Beijing Institute of Heart Lung and Blood Vessel Diseases, 2 Anzhen Road, Chaoyang District, Beijing 100029, China Full list of author information is available at the end of the article
}

associated with human PB19 in a cardiac intensive care unit (ICU).

\section{Case presentation}

A 69-year-old man with a history of mitral valvuloplasty 11 years prior and esophagectomy (esophageal cancer) 4 years prior received elective mitral valvular replacement and tricuspid valvuloplasty under cardiopulmonary bypass (CPB). The patient suffered dysfunction of the left limb after the operation, and a CT scan showed acute cerebral infarction. He was awake on postoperative day (POD) 3 and extubated on POD 4.

The patient's temperature increased to $38.5{ }^{\circ} \mathrm{C}$ in the morning of POD 8, with hypoxemia, heart rate of 115 beats per minute, respiratory rate of 30 breaths per minute, and a blood pressure of $130 / 62 \mathrm{mmHg}$ with norepinephrine $(0.07 \mu \mathrm{g} / \mathrm{kg} / \mathrm{min})$ infusion. Pulmonary 
auscultation revealed bilateral basal crackles. Arterial blood gas analysis with a noninvasive V60 ventilator (PHILIPS, New Zealand) (IPAP: $16 \mathrm{mmHg}$, EPAP: $8 \mathrm{mmHg}, \mathrm{FiO}_{2}: 100 \%$ ) at that time showed $\mathrm{pH} 7.244$, $\mathrm{PaO} 284.7 \mathrm{mmHg}, \mathrm{PaCO} 253.6 \mathrm{mmHg}$ and $\mathrm{PaO} 2: \mathrm{FiO}_{2}$ $(\mathrm{P} / \mathrm{F})<100 \mathrm{mmHg}$. Other laboratory data included a white blood cell count of $15.04 \times 10^{9} / \mathrm{L}$ with $92 \%$ neutrophils and $2.1 \%$ lymphocytes, platelet count of $81 \times 10^{9} / \mathrm{L}$, hemoglobin of $78 \mathrm{~g} / \mathrm{L}$ (preserved red cell $2 \mathrm{U}$ ), hematocrit of $21.9 \%$, blood lactate of $1.5 \mathrm{mmol} / \mathrm{L}$, and blood glucose of $10.9 \mathrm{mmol} / \mathrm{L}$. Immunologic condition evaluated on POD 11, showed decreased count of CD4+ and CD8+lymphocytes (CD4+: 107/ $\mu \mathrm{l}, \mathrm{CD} 8+: 42 / \mu \mathrm{l})$, as well as decreased count of B lymphocytes and natural killer cells.

Chest radiographs showed ground glass-like changes in the lung fields. A CT scan of the chest showed diffuse bilateral alveolar infiltration and consolidation (Fig. 1DF), compared with that on hospital admission (Fig. 1 A-C). Diagnosis of myocarditis or heart failure was not considered because transthoracic echocardiogram measurement was normal..

ARDS was confirmed by P/F and CT. Endotracheal reintubation and mechanical ventilation (840 ventilator system, NELLCOR PURITAN BENNETT, Ireland) were performed due to respiratory failure with bilevel mode
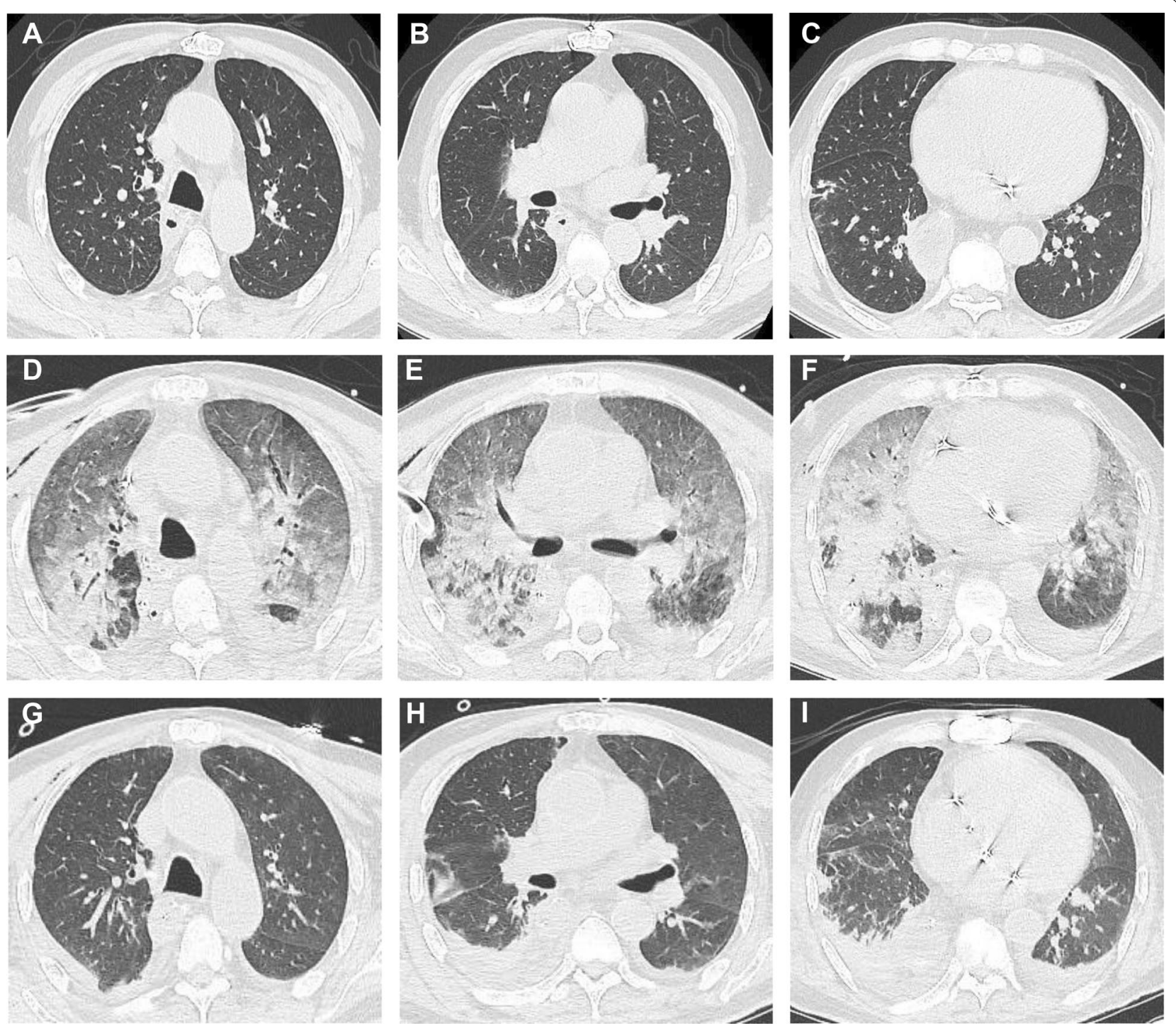

Fig. 1 The changes of chest CT. A-C on hospital admission. D-F 8 days after operation when the patient was reintubated. G-I 14 days after operation and 6 days after reintubation 
(PEEP high $\left._{18} \mathrm{mmHg}, \mathrm{PEEP}_{\text {low }}: 10 \mathrm{mmHg}, \mathrm{FiO}_{2}: 100 \%\right)$. Bronchoscopy was performed, which revealed a large quantity of clear serous secretions.

To identify the pathogen as soon as possible, we did blood culture and sputum culture before antimicrobial administration. Then detections of mNGS in serum and bronchoalveolar lavage fluid (BALF) were performed. Human PB19-specific nucleic acids were detected in both mNGS samples (Fig. 2A, B). Confirmatory examination showed that human PB19 IgM in serum was positive, while IgG was negative (Table 1). Meanwhile, ARDS of the patient occurred during the Corona Virus Disease 2019 (COVID-19) pandemics, the new coronal nucleic acid and antibodies were all negative. So, diagnosis of COVID-19 was excluded.

Empiric antibiotic administration (vancomycin and meropenem) was performed after sampling of blood culture and sputum culture, and discontinued until negative blood culture and sputum culture. The patient accepted prone position ventilation and thymopentin.

The patient's $\mathrm{P} / \mathrm{F}$ began to increase with radiographic improvement after three-day ventilation. The CT manifestation of chest improved greatly (Fig. 1G-I), then the patient was extubated after six-day ventilation. The patient was discharged from the ICU on POD 15 and discharged home on POD 22. With the improvement, the mNGS in serum showed reduced sequence numbers of parvovirus DNA (Fig. 2C). Before discharge home, the human PB19 IgM and IgG in serum were both positive (Table 1). We followed up the patient at one year, he was alive and in a good condition.

\section{Discussion}

Diseases with human PB19 infection are common in pediatric patients. It is likely that more severe illness occurs in adults than in children, and $80 \%$ of adults have comorbid arthralgias or arthritis. The virus is spread by respiratory droplets, secondary infection through
Table 1 The changes of IgM and IgG in serum

\begin{tabular}{lccl}
\hline & $\operatorname{lgM}^{*}$ (index) & $\operatorname{lgG}^{*}$ (index) & Normal range \\
\hline Day $11^{\text {a }}$ & 3.0 & $<0.10$ & $0-0.9$ \\
Day $22^{\mathrm{b}}$ & 17.0 & 8.3 & $0-0.9$ \\
\hline
\end{tabular}

a 11 days after operation and 3 days after re-intubation

${ }^{b} 22$ days after operation when the patient was discharged

*parvovirus B19 antibody

household contacts, or blood product treatment, especially factor VIII and factor IX concentrates [4].

Respiratory involvement due to human PB19 has been documented [5-7] (especially in patients with immune suppression and in children). Two previously reported cases suffered dry cough and interstitial pneumonia [8]. However, ARDS caused by human PB19 appears extremely rare in adults at perioperative period. The evidence supporting acute human PB19 infection in our case was derived from the presence of human PB19-specific nucleic acids (in serum and BALF) and positive serum human PB19 IgM, and no other proven infection [9]. Furthermore, there was a significant alteration in serum IgM and IgG. In the early phase, IgM was positive, while IgG was negative. With the clearing of pulmonary infiltration, increased IgM was detected and IgG turned positive. It is usually considered that IgM is present 7-10 days following infection which indicates acute infection, while IgG is protective antibody which indicates past infection. Human PB19 DNA in serum appears 2-3 days after acute infection. But human PB19 DNA has been shown to persist in serum and synovial fluid for many years, which cannot be indicative of an acute infection. Through mNGS, a new choice for finding rare or atypical pathogens in severe complicated pneumonia [10], we narrowed the scope of suspected pathogens quickly. Thus, a combination of serum human PB19 DNA by mNGS and serum human PB19 IgM could provide higher diagnostic sensitivity for acute human PB19 infection.

This patient's immunity level was low during his ICU stay. Although the patient had tumor history, he did not
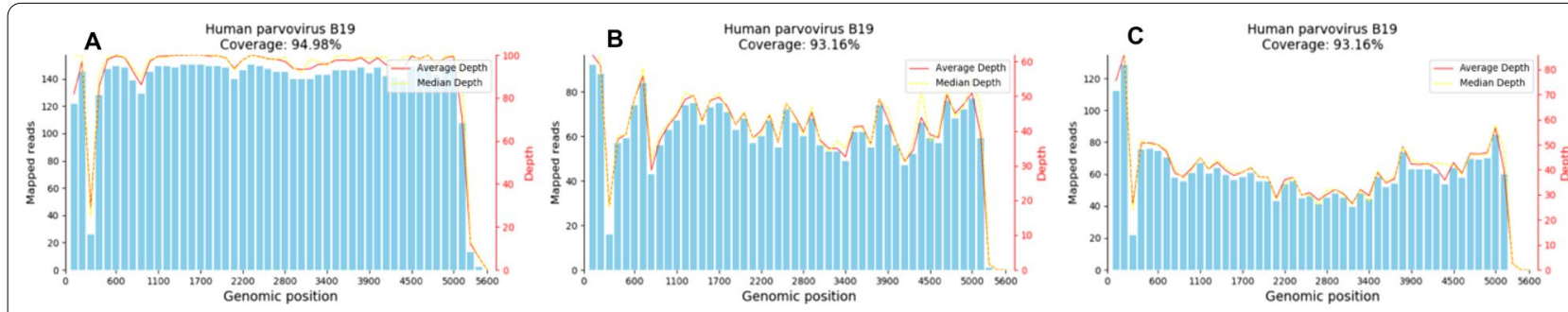

Fig. 2 mNGS for human parvovirus B19 in the early phase and the recovery phase. A mNGS of the serum (8 days after operation when the patient was reintubated). $\mathbf{B}$ mNGS of the BALF (8 days after operation when the patient was reintubated). $\mathbf{C}$ mNGS of the serum (14 days after operation and 6 days after reintubation). $m N G S$ metagenomic next-generation sequencing, BALF bronchoalveolar lavage fluid 
receive chemotherapy before and after cardiac surgery. It is considered that the immune dysfunction has relationship with cardiac surgery injury, CPB, blood loss and malnutrition [11]. Finally, immunodepression may increase susceptibility to infection [12]. We should be vigilant against virus infection.

How the reported patient became infected is unclear. During the perioperative period, another patient (suspected patient) in the same surgical ward had the same manifestations. The severe pulmonary infiltration of this suspected patient was accentuated in one week, and human PB19 was detected in the serum by mNGS after discharge home. Both of the patients had blood transfusions, but the two patients had different blood types. It was impossible that they had the same lot of blood transfusion.

Outbreaks of human PB19 infection among patients have been reported in adult surgical wards [13]. Although there was no evidence revealing the relationship between these two patients, no more cases appeared after terminal disinfection of the ward. These two patients from different areas were followed up for one month, there was no outbreak in their communities.

The precise mechanism of human PB19 pneumonia is unclear. It is uncertain whether lung injury is caused by direct infection or a secondary immune response from the host. The infection is usually self-limited. Specific antiviral therapy is unavailable to treat human PB19 infection [1]. Intravenous immunoglobulin (IVIG) has been proven to be effective in pure red cell aplasia or immunosuppression [14]. However, the efficiency of IVIG in immunocompetent patients is unclear [3]. Support therapies such as intubation, prone positioning, and protective ventilation were important in this case.

In conclusion, human PB19 should be considered in the differential diagnosis of unknown pneumonia for immunodeficiency patients. The determination of human PB19 antibodies, especially positive serum IgM, and the human B19-specific nucleic acids in serum should be examined for the accurate diagnosis of acute human PB19 infection $[9,15]$. mNGS may be a new choice for finding rare or atypical pathogens in severe complicated pneumonia, especially for some virus [10].

\footnotetext{
Abbreviations

PB19: Parvovirus B19; mNGS: Metagenomic next-generation sequencing; ARDS: Acute respiratory distress syndrome; ICU: Intensive care unit; POD: Postoperative day; CPB: Cardiopulmonary bypass; BALF: Bronchoalveolar lavage fluid; COVID-19: Corona Virus Disease 2019; IVIG: Intravenous immunoglobulin.
}

Acknowledgements

We thank Dr. Hui Zeng (Beijing Shijitan Hospital) for his valuable discussion.

\section{Authors' contributions}

MM and HW contributed to collecting and analyzing the patient data. MM and $\mathrm{MJ}$ contributed to drafting of the manuscript. XM, XH and HW contributed to critical revision of the final version. All authors read and approved the final manuscript.

\section{Funding}

This project was supported by Mega-projects of Science and Technology Research of China 2018 YFE9102500 (to Hong Wang).

\section{Availability of data and materials}

The datasets used and/or analyzed during the current study are available from the corresponding author on reasonable request.

\section{Declarations}

Ethics approval and consent to participate

Not applicable.

\section{Consent for publication}

Written informed consent was obtained from the patient for publication of this Case report and any accompanying images. A copy of the written consent is available for review by the Editor of this journal.

\section{Competing interests}

The authors declare that they have no competing interests.

\section{Author details}

${ }^{1}$ Center for Cardiac Intensive Care, Beijing Anzhen Hospital, Capital Medical University, Beijing Institute of Heart Lung and Blood Vessel Diseases, 2 Anzhen Road, Chaoyang District, Beijing 100029, China. ${ }^{2}$ Department of Infectious

Diseases, Peking Union Medical College Hospital, Chinese Academy of Medical Sciences \& Peking Union Medical College, Beijing 100730, China.

Received: 11 July 2021 Accepted: 28 February 2022

Published online: 07 March 2022

References

1. Rogo LD, Mokhtari-Azad T, Kabir MH, Rezaei F. Human parvovirus B19: a review. Acta Virol. 2014;58(3):199-213.

2. Cossart YE, Field AM, Cant B, Widdows D. Parvovirus-like particles in human sera. Lancet. 1975;1(7898):72-3.

3. Young NS, Brown KE. Parvovirus B19. N Engl J Med. 2004;350(6):586-97.

4. Azzi A, Morfini M, Mannucci PM. The transfusion-associated transmission of parvovirus B19. Transfus Med Rev. 1999;13(3):194-204.

5. Janner D, Bork J, Baum M, Chinnock R. Severe pneumonia after heart transplantation as a result of human parvovirus B19. J Heart Lung Transplant. 1994;13(2):336-8.

6. Morris CN, Smilack JD. Parvovirus B19 infection associated with respiratory distress. Clin Infect Dis. 1998;27(4):900-1.

7. Ferraz C, Cunha F, Mota TC, Carvalho JM, Simões JS, Aparicio JM. Acute respiratory distress syndrome in a child with human parvovirus B19 infection. Pediatr Infect Dis J. 2005;24(11):1009-10.

8. Lipsker D, Boeckler P. Acute urticaria and dry cough with interstitial pneumonia: a clue for the diagnosis of primary parvovirus B19 infection. Clin Exp Dermatol. 2006;31(3):473-4.

9. Miron D, Luder A, Horovitz Y, Izkovitz A, Shizgreen I, Ben David E, Ohnona FS, Schlesinger Y. Acute human parvovirus B-19 infection in hospitalized children: a serologic and molecular survey. Pediatr Infect Dis J. 2006;25(10):898-901.

10. Chen X, Ding S, Lei C, Qin J, Guo T, Yang D, Yang M, Qing J, He W, Song $M$, et al. Blood and bronchoalveolar lavage fluid metagenomic nextgeneration sequencing in pneumonia. Can J Infect Dis Med Microbiol. 2020;2020:6839103.

11. Gaudriot B, Uhel F, Gregoire M, Gacouin A, Biedermann S, Roisne A, Flecher E, Le Tulzo Y, Tarte K, Tadié JM. Immune dysfunction after cardiac surgery with cardiopulmonary bypass: beneficial effects of maintaining mechanical ventilation. Shock. 2015;44(3):228-33. 
12. Angele MK, Faist E. Clinical review: immunodepression in the surgical patient and increased susceptibility to infection. Crit Care. 2002;6(4):298-305.

13. Seng C, Watkins P, Morse D, Barrett SP, Zambon M, Andrews N, Atkins M, Hall S, Lau YK, Cohen BJ. Parvovirus B19 outbreak on an adult ward. Epidemiol Infect. 1994;113(2):345-53.

14. Moudgil A, Shidban H, Nast CC, Bagga A, Aswad S, Graham SL, Mendez $\mathrm{R}$, Jordan SC. Parvovirus B19 infection-related complications in renal transplant recipients: treatment with intravenous immunoglobulin. Transplantation. 1997;64(12):1847-50.

15. Zerbini M, Gallinella G, Cricca M, Bonvicini F, Musiani M. Diagnostic procedures in B19 infection. Pathol Biol (Paris). 2002;50(5):332-8.

\section{Publisher's Note}

Springer Nature remains neutral with regard to jurisdictional claims in published maps and institutional affiliations.

- fast, convenient online submission

- thorough peer review by experienced researchers in your field

- rapid publication on acceptance

- support for research data, including large and complex data types

- gold Open Access which fosters wider collaboration and increased citations

- maximum visibility for your research: over $100 \mathrm{M}$ website views per year

At BMC, research is always in progress.

Learn more biomedcentral.com/submissions 